Revista de

Contabilidade e

Organizações

www.rco.usp.br
DOI: http://dx.doi.org/10.11606/rco.v10i27.118704
Journal of

Accounting and

Organizations

\title{
Estrutura de financiamento das firmas de energia elétrica no Brasil: uma abordagem à Pecking Order Theory (POT)
}

José Antonio De Françaa; Sandra Isaelle Figueiredo Dos Santos ${ }^{\mathrm{a}}$; Wilfredo Sosa Sandoval ${ }^{\mathrm{b}}$; Átila Pires Dos Santos ${ }^{\mathrm{c}}$

a Universidade de Brasilia

${ }^{b}$ Universidade Católica de Brasília

c Instituto Federal de Educação, Ciência e Tecnologia de Brasília

\section{Informações do Artigo}

Histórico do Artigo

Recebido: 20 de dezembro de 2015

Aceito: 17 de agosto de 2016

Palavras chave:

Pecking Order Theory e Estrutura de Capital.

Relacionamento do Uso Preponderante de Capital Próprio (UPC) com Retorno Preponderante de Capital (RPC).

Preferência por formas de financiamento das firmas de energia elétrica.

\begin{abstract}
Resumo
Este artigo discute resultados de pesquisa sobre formas de financiamento do negócio de energia elétrica no Brasil, por controle de capital, utilizando amostra de 31 firmas, de 1997 a 2013. A pesquisa investiga como essas firmas são preponderantemente financiadas, por capital próprio (CP) seguindo a Pecking Order Theory (POT) ou capital de terceiros (CT), e ainda como financiamento e taxa de retorno se relacionam. O objetivo é analisar as formas de financiamento e a relação do uso preponderante de capital (UPC) com retorno preponderante de capital (RPC). A metodologia utiliza modelos analíticos e regressão linear multivariada para obtenção dos resultados. Os resultados sugerem que as firmas tem financiamento compatível com a POT; a relação entre $\mathrm{CP}$ e CT é menor nas firmas com controle privado; o retorno das firmas com controle privado é superior ao das firmas com controle governamental, o UPC com deslocamento dinâmico, é inverso ao RPC. A pesquisa inova e se diferencia por relacionar UPC com RPC.

Copyright $@ 2016$ FEA-RP/USP. Todos os direitos reservados
\end{abstract}

\section{INTRODUÇ̃̃O}

Energia elétrica como commodity de uso sustentável depende das estruturas de geração, transmissão, e distribuição, que requerem investimentos de longo prazo e impõem elevado custo sócio-econômico. Por ser um dos principais componentes da infraestrutura de um país, energia elétrica também é uma das bases do crescimento e do desenvolvimento da indústria que gera emprego e produz riqueza, cujo desempenho é capturado por indicadores como Produto Interno Bruto (PIB) e bem-estar social, e se torna uma restrição ao crescimento em período em que a geração, transmissão e distribuição são escassas. Escassez no fornecimento de energia elétrica provoca crise ou caos social, com perdas em segmentos econômicos e domésticos, como ocorrera nos Estados Unidos, Canadá, Itália, Indonésia, Colômbia, Argentina (Canzian, 2003) e vem ocorrendo no Brasil.

No Brasil, resultados do PIB do segundo trimestre de 2014 (IBGE, 2014) mostram que dentre as atividades da Indústria, uma que apresenta desempenho positivo é o próprio segmento de energia elétrica $(3,1 \%)$. Outro sinalizador do impacto desse segmento na economia é que no ano de 2014 significativas firmas do negócio de energia elétrica estavam entre as que tiveram papéis mais valorizados, alavancando para cima o IBOVESPA (BM\&FBOVESPA, 2014). Esses indicadores sinalizam a relevância da indústria de energia elétrica no contexto econômico, ainda por considerar que à medida que a economia cresce, aumenta a demanda pelo consumo dessa commodity, sendo um indicador de comportamento pró-cíclico.

Marco importante dessa indústria no Brasil é que a partir de meados da década de 90 do século XX, o negócio de energia elétrica experimentou mudanças estruturais, por meio de privatizações e desestatizações, tornando-o atrativo para investimento, com participação governamental e privada, quebrando o monopólio estatal

Autor Correspondente: Tel (61) 34907388

E-mail: franca@itecon.com.br (J. A. França); sandraisaelle@gmail.com (S. I. F. Santos); sosa.s.wilfredo@gmail.com (W. S. Sandoval);

atilapires@gmail.com (A. P. Santos)

Universidade de Brasília - Campus Darcy Ribeiro - Asa Norte - 70910900 - Brasília, DF - Brasil 
(HIROTA, 2006) e alinhando-se com o que já vinha ocorrendo em outras partes do mundo (JOSKOW, 2003).

Inserido neste contexto, o artigo traz como motivação analisar e discutir as formas de financiamento das firmas do negócio de energia elétrica listadas na BM\&FBOVESPA, em operação no Brasil, no período de 1997 a 2013, segregadas por controle de capital, de origem governamental e privada, cuja amostra é composta por 31 firmas, em que 21 são de controle privado e 10 são de controle governamental. Para identificar a preferência das firmas pelas formas de financiamento dos investimentos a pesquisa inova com a utilização de dois indicadores: (a) uso preponderante de capital (UPC) e (b) retorno preponderante de capital (RPC), por meio de escalonamento dinâmico das observações da distribuição, sendo o UPC o indicador que revela a intensidade do uso do capital próprio (CP) em relação ao capital de terceiros (CT); o RPC a combinação do retorno sobre ativos (ROA) com o UPC que, de forma associada, podem sugerir a estrutura de capital de preferência da firma.

Estrutura de capital, de forma recorrente, é estudada por pesquisadores na tentativa de obter sinalizações da estrutura ótima de financiamento com modelos acadêmicos; na gestão corporativa o interesse é utilizar CP e CT no nível de combinação que permita o maior retorno para os investidores e máximo valor da firma. No entanto, em que pese algumas pesquisas avançadas estarem disponíveis, ainda não há evidências que confirmem um padrão que possa ser dado como ótimo nem tão pouco um modelo único para garantir a forma de financiamento ótima (BRITO; CORRAR; BATISTELLA, 2007; MYERS, 2001; DURAND 1952; MODIGLIANI; MILLER, 1958; FAMÁ; BARROS; SILVEIRA, 2001 AHN; DENIS; DENIS, 2006; FERREIRA; VILELA, 2004; FIGUEIREDO, 2007; HOVAKIMIAN, OPLER e TITMAN, 2001; FAMA e FRENCH 2002; MEDEIROS; DAHER, 2008; BASTOS; NAKAMURA e BASSO, 2009; BARROS, 2005; IQUIAPAZA; AMARAL; ARAÚJO; 2008; CORREA; BASSO; NAKAMURA, 2013; IARA, 2013).

Desde Modigliani e Miller (1958) estudos sobre estrutura ótima de capital das firmas têm recebido focos distintos e buscam obter sinalizações de que fatores determinam a questão do financiamento. As teorias existentes sugerem que as firmas selecionam sua estrutura de capital (ou grau de endividamento) de acordo com atributos próprios que determinam os vários custos-benefícios associados às decisões de financiamento (PEROBELLI; FAMÁ, 2002).

Myers (1984) estudou a estrutura de capital de firmas e obteve evidências de que a forma preferencial de financiamento é com CP e quando há necessidade de buscar CT, há um critério seletivo do endividamento, colocando como última opção a emissão de dívidas. A evidências desse estudo, na literatura, é conhecida como Pecking Order Theory (POT).

Diante da relevância da discussão, a questão problema que permeia o presente estudo pretende obter uma sinalização de como as firmas do negócio de energia elétrica no Brasil, com controle governamental e privado, são preponderantemente financiadas, com $\mathrm{CP}$ ou CT, qual a relação entre essas duas formas de financiamento, bem como a associação delas com o ROA.

Como condição necessária para obter sinalização de reposta ao problema declarado a pesquisa tem por objetivo analisar as formas de financiamento das firmas do negócio de energia elétrica, com controle governamental e privado operando no Brasil, e o relacionamento entre o ROA e o UPC. Para conduzir o objetivo da pesquisa e permitir obtenção de resposta à investigação são utilizados modelos quantitativos analíticos e regressivos como se declara mais adiante na seção de metodologia.

A relevância da pesquisa está centrada na importância da análise da estrutura de capital das firmas do negócio de energia elétrica, e no fato de inovar com a utilização dos indicadores de UPC e RPC, não encontrados em pesquisa semelhante, que são a principal contribuição do estudo. O segmento do negócio de energia elétrica é escolhido pela sua importância na infraestrutura e na matriz de produção brasileira; o período de 1997 a 2013 foi eleito por ser o período em que as reformas estruturais que promoveram as privatizações e desestatizações estavam definidas e chegavam à fase conclusiva; a extensão do escalonamento dinâmico foi determinada em função do tempo de permanência de um governo no Brasil nas últimas décadas.

A pesquisa está estruturada de acordo com as seções seguintes em que a discussão teórica (2) apresenta os principais achados e evidências de pesquisas anteriores; metodologia e amostra (3) descrevem o método de pesquisa utilizado, sustentado em modelos analítico e regressivo, e análise da amostra com evidências preliminares; análise dos resultados (4) foca a análise descritiva e inferencial em que se relacionam as respostas do modelo com o problema de pesquisa; conclusões (5) apresentam as principais evidências associadas com o problema de pesquisa obtidas com a aplicação dos modelos; e por fim as referências que sustentam a discussão teórica. 


\section{DISCUSSÃO TEÓRICA}

Nesta seção são trazidos para discussão resultados de estudos relacionados com o negócio de energia elétrica e com a Pecking Order Theory (POT), oriundos de trabalhos teóricos e empíricos, que subsidiam e sustentam os achados da presente pesquisa.

Na década de 80 do século XX havia um cenário econômico de fixação de preços e encargos, aumento da carga tributária e endividamento externo, que provocaram progressivas quebras do equilíbrio econômicofinanceiro do setor de energia elétrica no Brasil e ainda, em meados da década de 90, após a implementação do plano real, a apreciação cambial e a abertura comercial, promoveram desequilíbrio externo devido ao aumento da concorrência internacional, tendo como consequência a deterioração do saldo do balanço de pagamentos que antecedeu o processo de privatizações e desestatizações de empresas com entrada de capitais no país (SILVA, 2011). Diante desse contexto de privatizações e desestatizações a Lei $9.427 / 96$ criou a Agência Nacional de Energia Elétrica (ANEEL) para regular o negócio de energia elétrica no Brasil, e que uma das regras foi não permitir a verticalização das atividades de geração, impedindo que uma firma opere em mais de uma dessas atividades.

No contexto da geração, transmissão e distribuição da energia elétrica, não se localizou sinalização fática de relacionamento da interrupção de energia elétrica com restrição de financiamento ou estrutura de capital, embora várias interrupções (black out) tenham ocorrido ao longo da história recente nos Estados Unidos, Canadá, Itália, Indonésia, Colômbia, Argentina (CANZIAN, 2003), e no Brasil.

Araújo (2001), discute o insucesso das reformas do sistema de energia elétrica no Brasil. Argumenta que a política energética deve basear-se no reconhecimento de que a demanda por eletricidade tende a crescer rapidamente em futuro previsível e que a reforma deve centrar-se no investimento e na eficiência dinâmica, e que o grande sistema hidrelétrico do Brasil precisa de tratamento especial para investimentos em plantas hidráulicas e térmicas. Corroborando esse posicionamento, Silvestre et al. (2010) declaram que empresas públicas do setor de energia elétrica passam por inconsistências e descontinuidade quanto às políticas governamentais e ausência de incentivos para a melhoria de indicadores financeiros.

A estrutura de capital do setor de energia elétrica sofre impacto da regulação da ANEEL, tendo em vista que para permitir financiamento de banco que oferece taxa subsidiada (inferior à inflação) aquela Agência editou a Resolução Normativa ${ }^{\circ}$ 592/2013 disciplinando que as firmas candidatas ao financiamento tenham fluxo de caixa livre, antes do pagamento da dívida, $30 \%$ maior que a parcela de pagamento incluindo a amortização mais os juros. Diante do baixo custo de captação dessa dívida, em relação às taxas correntes do mercado, a estrutura de capital das firmas poderia ser artificialmente impactada, alterando a combinação de capital próprio (CP) e capital de terceiros (CT) e ainda as características do negócio (MYERS, 2001). Como em Albuquerque (2013), a estrutura de capital pode ser entendida como a proporção de $\mathrm{CP}$ em relação ao CT sinalizando a preferência da firma ou do segmento de negócio.

Embora estrutura de capital tenha sido amplamente testada por meio de trabalhos empíricos, não se chegou a uma teoria consolidada a respeito da preferência por financiamento. Uma das divergências das correntes teóricas é, por exemplo, se a forma como a firma se financia exerce influência ou não sobre seu valor. Diante desse questionamento há duas correntes opostas: a teoria tradicional representada por Durand (1952); e a teoria proposta por Modigliani e Miller (1958).

Segundo Famá, Barros e Silveira (2001), a teoria tradicional defende que o custo de capital de terceiros é menor que o custo de capital próprio e em função disso a firma deveria ter como meta o custo de capital mínimo para maximizar seu valor por meio da estrutura ótima de capital. Em contraponto, Modigliani e Miller (1958) argumentam que a estrutura de capital não afeta o valor da firma, uma vez que o custo dessa estrutura não se altera com o nível de financiamento. Assim, diante das divergências teóricas ainda não se consideraria a existência de modelo de estrutura ótima de capital.

O estudo de Myers (1984) sinaliza uma hierarquia de financiamentos em que a firma prefere se financiar. Assim, primeiramente a firma utilizaria (a) recursos internos; se o endividamento for necessário, a firma preferiria (b) títulos da dívida; posteriormente a preferência seria por (c) títulos híbridos (como debêntures conversíveis); e como última alternativa, (d) emissão de dívida. Essa hierarquia de preferências, como corrente teórica, é denominada Pecking Order Theory (POT). O estudo apresenta uma série de razões porque as firmas preferem se financiar com capital próprio como, por exemplo, o risco de sub-precificação ao emitir ações ao mercado, uma vez que os acionistas poderiam precificar o fluxo de caixa da firma com deságio por não terem o mesmo conhecimento dos administradores. Outro ponto a ser considerado é o custo de empréstimo e falência, de deixar uma folga financeira para somente quando a firma precisar pedir empréstimo. 
Outras abordagens relacionam estrutura de capital com influência de fatores macroeconômicos e institucionais. Rajan e Zingales (1995), exploram características como (a) tamanho, em que grandes firmas tendem a um endividamento maior; (b) magnitude dos ativos fixos, afeta positivamente a estrutura de capital; (c) lucratividade e valor da firma em relação ao valor contábil, relacionam-se de forma inversa com o índice de endividamento. Ahn, Denis e Denis (2006) argumentam que a literatura de estrutura de capital declara que alavancagem financeira e investimento são fortemente relacionados, por considerar que a alavancagem aumenta a probabilidade de falência para reduzir a probabilidade de sofrer dificuldades financeiras e, em função disso, esperar-se-ia que firmas com maior alavancagem mantenham maior nível de caixa. Por outro lado, à medida que o grau de alavancagem atua como proxy para a capacidade das firmas emitir dívida, também se esperaria que firmas com maior alavancagem tenham menor índice de liquidez (FERREIRA; VILELA, 2004).

Em síntese, os argumentos expostos mostram que há diversas abordagens para se compreender a política de estrutura de capital, que vão além de questões como maximização do valor da firma, e que influenciam os agentes na escolha das fontes de financiamento. É com esta compreensão que a presente pesquisa pretende contribuir com a literatura do gênero propondo a combinação dos indicadores, uso preponderante de capital (UPC) com retorno preponderante de capital (RPC) e retorno dos ativos (ROA), na perspectiva de obter uma associação com a abordagem lógica da POT no contexto das firmas da indústria de energia elétrica em operação no Brasil, porque partindo do estudo de Myers (1984) vários outros estudos sugerem a POT como capaz de explicar a política de estrutura de capital das firmas.

Hovakimian, Opler e Titman (2001) concluem em seu estudo que as firmas preferem se financiar utilizando lucros retidos, mas acreditam que os agentes se motivam em busca do custo de capital mínimo, procurando a estrutura ótima de capital. Seguindo nesta mesma linha Fama e French (2002) concluíram em seu estudo que firmas mais lucrativas são menos endividadas, confirmando a abordagem teórica da POT, conclusões semelhantes que também obtiveram Medeiros e Daher (2008); Bastos, Nakamura e Basso (2009) de que a POT explica as preferência pela estrutura de capital. Mas de forma contrária, o estudo de Barros (2005) não sinaliza evidências favoráveis à hipótese da hierarquização de fontes de financiamento, e é compartilhado pelos achados de Iquiapaza, Amaral e Araújo (2008) ao concluírem que a POT não pode ser considerada uma teoria geral para explicar a estrutura de capital das firmas. Por outro lado, Correa, Basso e Nakamura (2013) sugerem que a POT é mais consistente para explicar a política de estrutura de capital do que a teoria de trade-off, em estudo aplicado às firmas brasileiras de capital aberto, compartilhados por Iara (2013) ao constatar que as firmas brasileiras se orientam conforme a POT.

\section{METODOLOGIA E AMOSTRA}

A metodologia utilizada é positivista e os resultados são sustentados por modelos analíticos e regressão linear multivariada, com uso dos estimadores de mínimos quadrados ordinários (MQO), em que a variável dependente a ser explicada é a variação do ativo total $(\Delta \mathrm{AT})$ e as variáveis independentes, que explicam as variações do ativo total, são as variações do capital de terceiros $(\Delta C T)$, do capital próprio $(\Delta C P)$ e o retorno preponderante do capital (RPC) das firmas do negócio de energia elétrica, listadas na BM\&FBOVESPA, agrupadas por controle de capital, de 1997 a 2013. As regressões são rodadas no conjunto das firmas por controle de capital com escalonamento dinâmico em 10 períodos com intervalo de 8 anos.

Os resultados das regressões dos 10 períodos escalonadas (mostrados na Tabela 4), por controle de capital, são utilizados para testar a significância da $\Delta \mathrm{CT}$, da $\Delta \mathrm{CP}$ e do RPC em relação à variação do ativo total $(\Delta \mathrm{AT})$. Os indicadores obtidos pelos demais modelos analíticos são, de forma combinada, utilizados para associação com a abordagem teórica da POT.

Os dados primários, obtidos das demonstrações contábeis em moeda funcional, a partir dos quais são obtidas as variáveis de interesse da pesquisa, foram atualizados pela variação do IPCA (índice de preços ao consumidor amplo) para a base 2013. As variações do ativo total, do capital de terceiros e do capital próprio estão demonstradas pelos seus valores médios anuais da série para as firmas com controle governamental e privado.

\subsection{Modelos analíticos e regressão linear multivariada}


Nesta subseção se descrevem os modelos utilizados para calcular as variáveis de interesse exigidas pelo objetivo e problema de pesquisa por meio das equações seguintes. Referidos modelos são alimentados pelos dados das variáveis contábeis recuperadas das demonstrações financeiras padronizadas para usuários externos. Os dados das firmas com controle privado são identificados por $(\mathrm{P})$ e das firmas com controle governamental são identificados por $(\mathrm{G})$.

a) Variação do ativo total $(\Delta \mathrm{AT})$

O resultado desta função indica a variação média do ativo total, por firma e controle, em cada ano, em termos unitários.

$$
\Delta A T_{j, t}^{k}=\frac{A T_{j, t}^{k}-A T_{j, t-1}^{k}}{A T_{j, t-1}^{k}}, k=(P, G)
$$

em que AT é ativo total; t é o período anual; j é a firma.

b) Variação do capital de terceiros $(\Delta \mathrm{CT})$

Esta função exibe como resultado a variação média do uso do capital de terceiros, por firma em cada ano.

$$
\Delta C T_{j, t}^{k}=\frac{C T_{j, t}^{k}-C T_{j, t-1}^{k}}{C T_{k, t-1}^{k}}, k=(P, G)
$$

em que CT é a dívida de longo prazo (passivo não circulante); t é o período anual; j é a firma.

c) Variação do capital próprio $(\Delta \mathrm{CP})$

Como resultado esta função mostra a variação do uso do capital próprio. Este resultado inclui a variação do capital líquido gerado pelas atividades mais aportes efetuados pelos acionistas.

$$
\Delta C P_{j, t}^{k}=\frac{C P_{j, t}^{k}-C P_{j, t-1}^{k}}{C P_{j, t-1}^{k}}
$$

em que CP é o patrimônio líquido; t é o período anual; e j é a firma.

d) Grau de endividamento (GE)

O resultado desta função mostra a relação entre as fontes de financiamento externo e o ativo total líquido na perspectiva do longo prazo. As variáveis contábeis CT e AT são os saldos consignados no balanço em cada ano.

$$
G E_{j, t}=\frac{C T_{j, t}^{k}}{A T_{j, t}^{k}}, \quad k=(P, G)
$$

em que CT é o capital de terceiros (dívida de longo prazo); AT é o ativo total líquido; j é a firma; e t é o período anual.

e) Retorno sobre o ativo (ROA)

Esta função exibe como resposta a relação entre o lucro líquido de cada período anual e o ativo total médio de cada firma, como medida de desempenho depois da dedução dos juros, depreciação e tributo direto.

$$
R O A_{j, t}=\frac{2 L L_{j, t}^{k}}{\left(A T_{j, t}^{k}+A T_{j, t-1}^{k}\right)}
$$

em que LL é o lucro líquido; AT é o ativo total; j é a firma; e t é o período anual.

f) Modelo teórico da regressão linear

Os estimadores desta regressão permitem responder o problema de pesquisa, sinalizando a preferência pela forma de financiamento dos ativos, com CP ou CT, de acordo com a significância estatística e magnitude dos coeficientes estimados, no total da amostra e por controle de capital.

$$
\Delta A T_{j, t}^{k}=\propto+\beta_{1} \Delta C P_{j, t-1}^{k}+\beta_{2} \Delta C T_{j, t-1}^{k}+\beta_{3} R P C_{j, t-1}^{k}+\in_{j, t}^{k}, \quad k=(T, P, G)
$$


em que $\Delta \mathrm{AT}$ é variação do ativo total; $\Delta \mathrm{CP}$ é variação do capital próprio (patrimônio líquido); $\Delta \mathrm{CT}$ é variação do capital de terceiros (dívida de longo prazo); RPC é o retorno preponderante de capital; j é firma; P é o controle privado; G é o controle governamental; T é total da amostra; t é o ano; $\alpha$ é o intercepto; $\varepsilon$ é o termo de erro.

g) Uso preponderante de capital (UPC)

O coeficiente desta relação é o resultado ponderado das variações do uso de capital próprio pelas variações do uso de capital de terceiros e quanto mais elevados for o coeficiente maior é o uso de capital próprio em relação ao capital de terceiros, sendo preponderante quando a relação for maior que e, se nesta condição, satisfazem a abordagem teórica da POT de que a preferência da firma é se financiar com capital próprio.

$$
U P C_{j, t}^{k}=\frac{C P_{j, t}^{k}-C P_{j, t-1}^{k}}{C P_{j, t-1}^{k}} \cdot\left[\frac{C T_{j, t}^{k}-C T_{j, t-1}^{k}}{C T_{j, t-1}^{k}}\right]^{-1}, k=(P, G) ;\left(\frac{C T_{j, t}^{k}-C T_{j, t-1}^{k}}{C T_{j, t-1}^{k}}>0 ;\right) ; C P_{j, t-1}^{k}>0
$$

em que CP é o capital próprio; CT é o capital de terceiros; j é a firma; e t é período do deslocamento dinâmico.

h) Retorno preponderante de capital (RPC)

O coeficiente resultante desta função sinaliza, de forma ponderada, o retorno do investimento em relação ao uso preponderante do capital próprio e quanto menor for o coeficiente mais expressivo é o uso do capital próprio em relação ao capital de terceiro e, se nesta condição, tende a satisfazer a abordagem teórica da POT de que a firma prefere se financiar com capital próprio.

$$
R P C_{j, t}^{k}=\frac{2 L L_{j, t}^{k}}{\left(A T_{j, t}^{k}+A T_{j, t-1}^{k}\right)} \cdot\left(\frac{\left(\frac{C P_{j, t}^{k}-C P_{j, t-1}^{k}}{C P_{t-1}^{k}}\right)}{\left(\frac{C T_{j, t}^{k}-C T_{j, t-1}^{k}}{C T_{j, t-1}^{k}}\right)}\right)^{-1},\left(A T_{j, t}^{k}+A T_{j, t-1}^{k}\right)>0 ;\left(\frac{C T_{j, t}^{k}-C T_{j, t-1}^{k}}{C T_{j, t-1}^{k}}\right)>0
$$

em que RPC é o coeficiente entre ROA e UPC; LL é o lucro líquido depois da depreciação juros e tributos diretos; AT é o ativo total; CP é o capital próprio; CT é o capital de terceiros; k é o controle de capital (P,G); j é a firma; t é período do deslocamento dinâmico.

As estatísticas descritivas complementam esta metodologia por meio dos estimadores da média, mediana, desvio padrão e coeficiente de variação de suas respectivas variáveis.

\subsection{Descrição da Amostra}

Os dados da amostra foram obtidos diretamente das demonstrações financeiras padronizadas de 31 firmas do negócio de energia elétrica, listadas na BM\&FBOVESPA, de 1997 a 2013 com periodicidade anual, segregadas por controle de capital, privado e governamental. As 31 firmas representam 47,76\% das firmas do negócio de energia elétrica em operação no Brasil, conforme classificação da BM\&FBOVESPA (2014). No entanto, dentro desse segmento de negócio, além da geração, transmissão e distribuição de energia elétrica, encontram-se firmas de participação e holdings, em que a relação com energia elétrica se limita à administração e ou participação em coligadas e controladas. As firmas selecionadas que iniciaram operação depois de 1997 apresentam dados zerados no período de pré-operação.

A segregação do controle societário, em governamental e privado, foi realizada por meio de consulta aos formulários cadastrais de cada uma das 31 firmas que compõe a amostra disponíveis no site da BM\&FBOVESPA, na parte de empresas listadas, relatórios financeiros. O resultado da consulta evidenciou que $21(67,74 \%)$ firmas tem controle privado e 10 (32,26\%) tem controle governamental, seja por meio dos governos federal, dos Estados ou Municípios.

As variáveis contábeis selecionadas foram (a) ativo total; (b) patrimônio líquido; (c) passivo circulante e não circulante; e (d) lucro líquido, a partir das quais foram calculadas as variáveis de interesse da pesquisa demonstradas na Tabela 1, utilizando os modelos descritos na subseção 3.1 precedente. Os dados estão organizados por ano totalizando 85 observações por firma na extensão da amostra, 357 observações para o conjunto das firmas com controle privado e 170 para o conjunto das firmas com controle governamental. 
Tabela 1: Variáveis de interesse da pesquisa consolidadas por ano extraídas da amostra de 31 firmas do negócio de energia elétrica no Brasil listadas na BM\&FBOVESPA por controle de capital de 1997 a 2013

\begin{tabular}{|c|c|c|c|c|c|c|c|c|c|c|}
\hline \multicolumn{6}{|c|}{ Controle Governamental (G) } & \multicolumn{5}{|c|}{ Controle Privado (P) } \\
\hline ANO & GE_G & $\Delta \mathrm{CT}$ TG & $\Delta \mathrm{CP}$ G & $\Delta$ AT_G & ROA_G & GE_P & $\Delta C T_{-} P$ & $\triangle \mathrm{CP} P \mathbf{P}$ & $\Delta \mathbf{A T} \_\mathbf{P}$ & ROA_P \\
\hline 1997 & 0,1954 & 0,0000 & 0,0000 & 0,0000 & 0,0422 & 0,2994 & 0,0000 & 0,0000 & 0,0000 & 0,0338 \\
\hline 1998 & 0,1509 & 1,5955 & 6,7894 & 4,1508 & 0,0214 & 0,3791 & 1,1223 & 0,5516 & 0,6763 & $-0,0013$ \\
\hline 1999 & 0,1926 & 0,1264 & $-0,1423$ & $-0,1176$ & 0,0137 & 0,3593 & 0,0651 & 0,0901 & 0,1236 & $-0,0007$ \\
\hline 2000 & 0,1938 & 0,3636 & 0,3349 & 0,3552 & 0,0233 & 0,4084 & 0,4475 & 0,2147 & 0,2734 & 0,0026 \\
\hline 2001 & 0,2190 & 0,1000 & $-0,0633$ & $-0,0266$ & 0,0279 & 0,3725 & 0,0331 & 0,0646 & 0,1327 & 0,0270 \\
\hline 2002 & 0,2923 & 0,2897 & $-0,1449$ & $-0,0339$ & $-0,0309$ & 0,4166 & 0,1068 & $-0,1869$ & $-0,0104$ & $-0,0716$ \\
\hline 2003 & 0,2631 & $-0,1693$ & $-0,0532$ & $-0,0771$ & 0,0173 & 0,3933 & $-0,0656$ & 0,0545 & $-0,0101$ & 0,0239 \\
\hline 2004 & 0,2449 & $-0,1183$ & $-0,0370$ & $-0,0528$ & 0,0239 & 0,4313 & 0,0153 & $-0,0561$ & $-0,0741$ & 0,0385 \\
\hline 2005 & 0,1935 & $-0,2758$ & 0,0148 & $-0,0834$ & 0,0277 & 0,3799 & $-0,1469$ & $-0,0029$ & $-0,0316$ & 0,0841 \\
\hline 2006 & 0,1641 & $-0,1703$ & 0,0337 & $-0,0220$ & 0,0297 & 0,3580 & $-0,0922$ & 0,0413 & $-0,0367$ & 0,0965 \\
\hline 2007 & 0,1638 & $-0,0165$ & $-0,0029$ & $-0,0144$ & 0,0354 & 0,3615 & $-0,0108$ & $-0,0148$ & $-0,0201$ & 0,1234 \\
\hline 2008 & 0,1847 & 0,1623 & $-0,0092$ & 0,0307 & 0,0474 & 0,3496 & $-0,0481$ & $-0,0139$ & $-0,0159$ & 0,1210 \\
\hline 2009 & 0,2209 & 0,1383 & $-0,0991$ & $-0,0481$ & 0,0274 & 0,3306 & $-0,9674$ & 0,0521 & 0,0184 & 0,1369 \\
\hline 2010 & 0,2358 & 0,0386 & $-0,0561$ & $-0,0272$ & 0,0376 & 0,3305 & 0,0724 & 0,2207 & 0,0726 & 0,1098 \\
\hline 2011 & 0,2133 & $-0,1099$ & 0,0047 & $-0,0158$ & 0,0480 & 0,3383 & $-0,0028$ & $-0,0494$ & $-0,0257$ & 0,1072 \\
\hline 2012 & 0,2235 & $-0,0557$ & $-0,1348$ & $-0,0990$ & $-0,0134$ & 0,3482 & 0,0056 & $-0,0538$ & $-0,0231$ & 0,0725 \\
\hline 2013 & 0,2540 & $-0,0080$ & $-0,1137$ & $-0,1270$ & $-0,0172$ & 0,3891 & 0,0884 & $-0,0714$ & $-0,0260$ & 0,0600 \\
\hline
\end{tabular}

Nota: GE: grau de endividamento; $\triangle \mathrm{CT}$ : variação do capital de terceiros; $\Delta \mathrm{CP}$ : variação do capital próprio; $\triangle \mathrm{AT}$ : variação ativo total; ROA: retorno sobre o ativo.

Fonte: Elaboração própria.

Preliminarmente se observa que os dados da coluna GE-G, em todo período amostral, apresentam valores inferiores aos da coluna GE_P, indicando que o endividamento das firmas com controle privado é superior ao das firmas com controle governamental e que para as duas formas de controle o endividamento de 2013 é superior ao de 1997, ainda que as variações totais do período sejam equivalentes (controle governamental 0,2540/0,1954 $=1,299$; controle privado $0,3891 / 0,2994=1,299$ ), sugerindo que o crescimento do endividamento foi igual para ambas as formas de controle.

Em termos teóricos a associação do GE com ROA deveria ser inversa, considerando que maior GE poderia implicar em maior custo do capital de terceiros em função de maior alavancagem financeira. Porém, firmas das duas formas de controle contrariam essa intuição teórica porque em 2000, 2001, 2008 e 2010 para o conjunto de firmas controle governamental e em 2000, 2004, 2007, 2008 e 2010 para o conjunto de firmas com controle privado, GE e ROA tiveram comportamento no mesmo sentido, GE aumentando/diminuindo quando ROA aumenta/diminui, que poderia ser explicado por dívida com baixo custo ou firma com baixa alavancagem, mas isto não foi explorado pela pesquisa.

As variações do ativo total $(\triangle \mathrm{AT})$ mostram que em ambas as modalidades de controle, a partir de 1998, houve reduções acentuadas dos investimentos. Dos 17 anos da série em 13 as firmas com controle governamental apresentam redução e nas firmas com controle privado 10 períodos. Os dados mostram que o último investimento significativo nos 17 anos ocorreu em $1998 \mathrm{em}$ que as firmas com controle governamental utilizaram maior proporção de capital próprio e as firmas com controle privado utilizaram maior capital de terceiro, isto já no início da crise energética que eclodiu em 1999.

\section{ANÁLISE DOS RESULTADOS}

Nesta seção estão apresentados os resultados obtidos com a aplicação dos modelos descritos em 3.1 utilizando os dados da Tabela 1 na subseção 3.2, por firma/ano e consolidado/ano. Esses resultados são evidenciados 
por meio das estatísticas descritivas, do modelo de regressão linear multivariada e da combinação dos indicadores. Os resultados das estatísticas descritivas contemplam todas as variáveis da pesquisa, enquanto que os resultados da regressão linear contemplam somente as variáveis $(\triangle \mathrm{CT}),(\triangle \mathrm{CP}),(\mathrm{RPC})$ e $(\triangle \mathrm{AT})$, nas formas de controle governamental e privado, com os dados organizados sob a forma de painel balanceado.

A Tabela 2 mostra os principais estimadores das estatísticas descritivas, das 21 firmas com controle privado e das 10 firmas com controle governamental. O estimador da média mostra que o grau de endividamento (GE) das firmas com controle privado $(0,333)$ é superior ao das firmas com controle governamental $(0,241)$, corroborado pela média das variações do capital de terceiros $\Delta \mathrm{CT}$ P $=0,845$ e $\Delta \mathrm{CT} \mathrm{G}=0,434$, ainda que a variação do CT para ambas as formas de controle seja idêntica para como já sinalizado pela análise preliminar dos dados da amostra. Já o acréscimo dos investimentos $(\triangle \mathrm{AT})$ das empresas com controle governamental $(0,2617)$ é superior ao das empresas com controle privado $(0,0515)$, em função do investimento pré-crise (1998) como mostrado na Tabela 1 precedente, corroborado pela variação capital próprio $(\Delta \mathrm{CP})$, em que as empresas com controle governamental apresentam variação positiva $(0,421)$ e as com controle privado apresentam variação negativa $(-0,046)$. Pelo lado do desempenho (ROA), as empresas com controle privado apresentam retorno $(0,051)$ maior do que as empresas com controle governamental $(0,030)$. Esses indicadores médios sinalizam que a capitalização das empresas com controle governamental foi em torno de 10 vezes maior do que a capitalização das firmas com controle privado, mas que não foi utilizada para investimento novo tendo em vista que o aumento do ativo das firmas com controle governamental em relação às firmas com controle privado ficou em torno de 5 vezes.

Comparando-se média e mediana, os dados mostram que, em relação ao grau de endividamento (GE), as firmas com controle privado vem de uma distribuição normal, considerando-se a proximidade entre os dois estimadores. Nas demais variáveis, tanto para o controle privado quanto para o controle governamental essa tendência se apresenta com maior assimetria em que mais da metade dos dados está abaixo da média. O estimador do coeficiente de variação mostra significativa dispersão nos dados da distribuição das variáveis $(\Delta \mathrm{CT}),(\Delta \mathrm{CP})$ e $(\Delta \mathrm{AT})$, moderada dispersão nos dados da distribuição do ROA e baixa dispersão nos dados da distribuição do GE, para ambas as formas de controle.

Tabela 2. Estatística descritiva dos dados amostrais das 31 firmas brasileiras do negócio de energia elétrica listadas na BM\&FBOVESPA de 1997 a 2013 por controle de capital

\begin{tabular}{|c|c|c|c|c|c|c|c|c|c|c|}
\hline \multicolumn{6}{|c|}{ Controle Privado (P) } & \multicolumn{5}{|c|}{ Controle Governamental (G) } \\
\hline Estimadores & GE_P & $\Delta \mathrm{CT} \mathbf{T}_{-} \mathbf{P}$ & $\Delta C P \_P$ & $\Delta$ AT_P & ROA_P & GE_G & $\Delta \mathrm{CT}$ _G & $\Delta C P \_G$ & $\Delta$ AT_G & ROA-G \\
\hline Média & 0,333 & 0,845 & $-0,0460$ & 0,0515 & 0,051 & 0,241 & 0,4347 & 0,4211 & 0,2617 & 0,0304 \\
\hline Mediana & 0,337 & $-0,019$ & $-0,0132$ & $-0,0149$ & 0,043 & 0,209 & $-0,0550$ & $-0,0070$ & $-0,0161$ & 0,0207 \\
\hline Desv pad & 0,203 & 9,722 & 1,5743 & 0,7447 & 0,125 & 0,155 & 4,6899 & 5,7075 & 2,8368 & 0,0780 \\
\hline Coef var & 0,609 & 1,495 & $-34,251$ & 14,456 & 2,444 & 0,644 & 10,789 & 13,555 & 10,840 & 2,5663 \\
\hline Mínimo & 0 & $-3,591$ & $-25,2944$ & $-1,0497$ & $-1,168$ & 0 & $-3,8644$ & $-22,1476$ & $-0,9973$ & $-0,1851$ \\
\hline Máximo & 1,131 & 170,90 & 6,926 & 10,475 & 0,752 & 0,591 & 58,846 & 67,606 & 36,059 & 0,3687 \\
\hline Observ & 357 & 357 & 357 & 357 & 357 & 170 & 170 & 170 & 170 & 170 \\
\hline
\end{tabular}

Legenda: GE: grau de endividamento; $\Delta \mathrm{CT}$ : variação do capital de terceiros; $\Delta \mathrm{CP}$ : variação do capital próprio; $\Delta \mathrm{AT}$ : variação ativo total; ROA: retorno sobre o ativo.

Fonte: Elaboração própria.

A Tabela 3 exibe os resultados da regressão linear multivariada, conforme modelo teórico descrito em (3.1f), rodado por mínimos quadrados ordinários (MQO), utilizando os dados amostrais de 31 empresas do negócio de energia elétrica no Brasil, totalizando 494 observações anuais, com defasamento de um ano. Os resultados mostram que (a) o coeficiente estimador da variação do capital próprio $(\Delta C P)$ é estatisticamente significativo a $99 \%$ de confiança e que o aumento de $1 \%$ na variação CP no ano anterior, tudo mais constante, reduz a variação do ativo $(\triangle \mathrm{AT})$ em 15,72\% no ano base; (b) o coeficiente estimador do retorno preponderante de capital (RPC) apresenta significância estatística com confiança de $90 \%$ e o crescimento de $1 \%$ no RPC do ano anterior, tudo mais constante, implica redução de $0,04 \%$ na $\triangle \mathrm{AT}$ do ano base; (c) em relação à variação do no capital de terceiros $(\Delta \mathrm{CT})$ o resultado do teste não mostra significância estatística. Os sinais dos coeficientes são coerentes com a abordagem teórica da Pecking Order Theory (POT), mostrando que o capital próprio é preferível ao capital de terceiros pela significância estatística da $\Delta \mathrm{CP}$, pelo reduzido coeficiente da RPC e pela não significância estatística da $\Delta$ CT. Estes sinais negativos confirmam o que já foi sinalizado pela análise da descrição da amostra de que significativa parte do aumento no capital próprio e capital de terceiros se destinou ao custeio. 
Para validar os requisitos básicos do MQO, de variância constante, ausências de autocorrelação e multicolinearidade, são utilizadas as estatísticas F, White, Durbin-Watson (DW) e Fator de Inflação da Variância (FIV). Os resultados do teste $\mathrm{F}(3,490)$ e heteroscedasticidade de White sinalizam variância constante ou ausência de heteroscedasticidade porque as estatísticas calculadas são inferiores às estatísticas padronizadas. A estatística DW cai na faixa de nenhuma autocorrelação positiva ou negativa porque a estatística calculada $(d=2,0047)$ é maior que o limite superior e menor que 4 vezes este limite, com significância estatística de 5\% e $1 \%$. O resultado do teste de multicolienaridade apresenta FIV entre 1 e 2 para as três variáveis explicativas sinalizando ausência de multicolinearidade por serem inferiores à estatística padronizada (FIV $=10)$. Complementarmente testou-se a consistência estrutural da série amostral por meio da estatística de Chow, cujo resultado $\mathrm{F}(4,486)$ é inferior à estatística padronizada a 10\%,5\% e 1\% de significância, sugerindo a ausência de falha estrutural nos dados amostrais. Com estes resultados os testes satisfazem os requisitos de MQO sendo portanto consistentes e significativos para responder a questão de pesquisa. $\mathrm{O}$ coeficiente de determinação $\mathrm{R}^{2}$ não tem relevância no resultado tendo em vista que o teste não tem valor preditivo.

Tabela 3. Resultado da regressão das variações do ativo $(\triangle \mathrm{AT})$ contra as variações do capital de terceiros $(\Delta \mathrm{CT})$ capital próprio $(\triangle \mathrm{CP})$ e retorno preponderante de capital $(\mathrm{RPC}) \mathbf{s}$

\begin{tabular}{|c|c|c|c|c|c|}
\hline & Coeficiente & Erro Padrão & Estatística-t & p-valor & \\
\hline Const & 6,3570 & 2,4972 & 2,5456 & 0,0112 & $* *$ \\
\hline$\Delta \mathrm{CT}_{-} 1$ & $8,6171 \mathrm{e}-05$ & $8,4923 e-05$ & 1,0147 & 0,3107 & \\
\hline$\Delta \mathrm{CP}_{-} 1$ & $-0,1572$ & 0,0065 & $-24,2985$ & 0,0000 & $* * *$ \\
\hline RPC 1 & $-0,0004$ & 0,0002 & $-1,7867$ & 0,0746 & $*$ \\
\hline R-quadrado & 0,0014 & \multicolumn{2}{|c|}{ R-quadrado ajustado } & & $-0,0047$ \\
\hline $\mathrm{F}(3,490)$ & 0,2268 & \multicolumn{2}{|c|}{$\begin{array}{l}\text { Test Chow falha estrutural } \\
\mathrm{F}(4,486)\end{array}$} & & 0,8777 \\
\hline Teste White heteroscedasticidade & 0,4955 & \multicolumn{2}{|c|}{ Durbin-Watson (DW) } & & 2,0047 \\
\hline Multicolinearidade (FIV) & $\Delta \mathrm{CT}_{-} 1=1,317$ & $\Delta \mathrm{CP} \quad 1=1,317$ & RPC_1 $1=1,000$ & & \\
\hline
\end{tabular}

Nota: GE: grau de endividamento; $\triangle \mathrm{CT}$ : variação do capital de terceiros; $\triangle \mathrm{CP}$ : variação do capital próprio; $\triangle \mathrm{AT}$ : variação ativo total; ROA: retorno sobre o ativo.

Fonte: Elaboração própria.

A Tabela 4 mostra os coeficientes das variáveis $\triangle \mathrm{CT}, \triangle \mathrm{CP}$ obtidos das regressões rodadas por MQO conforme definido em (3.1f) por controle de capital, escalonados em 10 períodos com intervalo de oito anos, e os coeficientes UPC e RPC obtidos pelos modelos descritos em 3.1g e 3.1h. Os indicadores de UPC, tanto para as empresas com controle governamental quanto para as empresas com controle privado, são superiores a 1, sinalizando que para ambos os controles de capital o uso de capital próprio é preferível ao do capital de terceiros, mas as empresas com controle governamental usam mais capital próprio do que as empresas com controle privado como mostra a magnitude dos indicadores e já sinalizado pelos coeficientes da regressão (Tabela 3) e estatísticas descritivas (Tabela 2), exceto para os intervalos 2003 a 2010 e 2004 a 2011. Os elevados indicadores de UPC nos intervalos de 2003 a $2010(12,1)$ e 2004 a $2011(5,8)$ nas empresas com controle privado, quando superam as empresas com controle governamental, reportam os coeficientes de variação do capital próprio e capital de terceiros não terem apresentado significância estatística a 5\% e a 10\%.

A Tabela 4 também mostra o RPC em relação ao UPC de forma dinâmica para as duas modalidades de controle de capital. Estes indicadores revelam que as firmas com controle privado, que usam menos capital próprio, têm melhor desempenho do que as firmas com controle governamental que usam mais capital próprio em relação ao capital de terceiros para financiamentos dos ativos. Desta forma o indicador RPC, em média, apresenta-se maior nas firmas com controle privado, mostrando melhor desempenho, em conformidade com o modelo teórico descrito em 3.1.h.

Estes resultados são relevantes e significativos considerando os efeitos dos deslocamentos dinâmicos ao longo da série, mostrando uma evolução crescente nos seis primeiros intervalos de oito anos, interrompendo de 2003 a 2010, e voltando a crescer nos intervalos seguintes. Com isso a análise dinâmica mostra-se preferível à análise estatística por mostrar a evolução/involução ao longo do tempo e permite ao pesquisador/usuário decidir com base na tendência de média móvel ao invés de um ponto médio estático. 
Tabela 4. Coeficientes das variações de capital de terceiros e capital próprio e uso preponderante de capital de 31 firmas de energia elétrica brasileiras listadas na BM\&FBOVESPA de 1997 a 2013 por controle de capital escalonados em 10 períodos

\begin{tabular}{|c|c|c|c|c|c|c|c|c|}
\hline PERÍODO & $\Delta C T \_P$ & $\Delta C P \_P$ & $\Delta \mathrm{CT}$ _G & $\Delta C P \_G$ & UPC_P & UPC_G & RPC_P & RPC_G \\
\hline 1997 a 2004 & 0,3024 & 0,4945 & 0,2288 & 0,8203 & 1,6354 & 3,5844 & 0,0026 & 0,0048 \\
\hline 1998 a 2005 & 0,3037 & 0,4885 & 0,2511 & 0,8028 & 1,6082 & 3,1969 & 0,0080 & 0,0047 \\
\hline 1999 a 2006 & 0,3920 & 0,4885 & 0,2602 & 0,8014 & 1,2461 & 3,0791 & 0,0192 & 0,0051 \\
\hline 2000 a 2007 & 0,4005 & 0,4571 & 0,2793 & 0,7588 & 1,1412 & 2,7170 & 0,0329 & 0,0067 \\
\hline 2001 a 2008 & 0,6444 & 0,6602 & 0,2537 & 0,6630 & 1,0244 & 2,6134 & 0,0499 & 0,0079 \\
\hline 2002 a 2009 & 0,1708 & 0,1921 & 0,2540 & 0,6864 & 1,1246 & 2,7027 & 0,0575 & 0,0075 \\
\hline 2003 a 2010 & 0,0371 & 0,4506 & 0,2571 & 0,6642 & 12,1371 & 2,5829 & 0,0073 & 0,0117 \\
\hline 2004 a 2011 & 0,0709 & 0,4138 & 0,2727 & 0,7500 & 5,8362 & 2,7494 & 0,0173 & 0,0124 \\
\hline 2005 a 2012 & 0,2076 & 0,2992 & 0,2569 & 0,6495 & 1,4414 & 2,5277 & 0,0736 & 0,0121 \\
\hline 2006 a 2013 & 0,1902 & 0,3234 & 0,2333 & 0,7836 & 1,7004 & 3,3579 & 0,0608 & 0,0078 \\
\hline
\end{tabular}

Como conclusão desta seção os resultados sinalizam que as firmas do negócio de energia elétrica no Brasil, independentemente da forma de controle, seguem a lógica da POT, mas as firmas alternam períodos de maior endividamento/menor retorno com maior endividamento/maior retorno; menor endividamento/maior retorno e menor endividamento/menor retorno, como mostram os dados das Tabelas 1 e 4 precedentes.

De forma geral, os testes revelam que, tanto para as firmas com controle privado, quanto para as com controle governamental, os resultados são similares aos de outros autores, no sentido de que há uma preferência no financiamento por capital próprio, revelando que o endividamento, em termos médios, para as firmas com controle privado $(33,37 \%)$ é maior do que para as firmas com controle governamental $(24,19 \%)$ como mostram as médias da Tabela 2, ainda que, em termos de variação, os dois grupos de controle de capital revelem que o capital terceiros cresceu mais do que o capital próprio. Mas quando se comparam os indicadores UPC e RPC dos dois grupos de controle há evidências significativas da preferência por financiamento do capital próprio em relação capital de terceiros.

Não obstante o financiamento dos investimentos por capital próprio ser preferido ao financiamento com capital de terceiros, o retorno dos investimentos é significativamente baixo, para as duas formas de controle, sendo o retorno das firmas com controle privado em torno de $5,15 \%$ e o retorno das firmas com controle governamental da ordem de 3,04\%. Considerando que a inflação brasileira no período da análise não foi inferior ao retorno médio obtido pelas empresas, o negócio de energia elétrica no Brasil não se mostra estimulante e pode ser uma das causas dos frequentes "apagões" no fornecimento de energia elétrica.

\section{CONCLUSÕES}

A principal motivação da pesquisa foi mostrar como as firmas do negócio de energia elétrica no Brasil, listadas na BM\&FBOVESPA, financiam seus investimentos. Os dados amostrais obtidos das demonstrações financeiras foram segregados em dois grupos, sendo um das empresas com controle privado (21) e outro das empresas com controle governamental (10), de 1997 a 2013. Neste sentido a pesquisa investigou a relação entre a variação do capital próprio $(\Delta \mathrm{CP})$, variação capital de terceiros $(\Delta \mathrm{CT})$, retorno preponderante de capital (RPC) e quanto essa relação impacta a variação do ativo; e ainda a relação entre o uso preponderante de capital (UPC) e o RPC.

Os coeficientes UPC e o RPC são a inovação da pesquisa por meio dos quais é possível avaliar o desempenho dinâmico das firmas e a preponderância do capital próprio, sendo estes o fator de diferenciação, com base em amostra de $67,74 \%$ das firmas com controle privado e $32,26 \%$ com controle governamental e os testes foram rodados por mínimos quadrados ordinários (MQO). 
Os resultados dos testes quantitativos medidos pelos modelos analíticos, econométricos e estatísticas descritivas, em média, trazem as seguintes reflexões:

a) as empresas brasileiras do negócio de energia elétrica, preponderantemente utilizam capital próprio (UPC > 1), compatível com a abordagem Pecking Order Theory (POT). Porém o UPC é menor nas firmas com controle privado sinalizando que o financiamento por capital próprio nas firmas com controle governamental é maior;

b) o retorno das firmas com controle privado é superior ao das firmas com controle governamental e mostra, em geral, relacionamento inverso entre UPC e RPC;

c) à medida que o aumenta (UPC > 1), mostrando maior expansão do capital próprio em relação capital de terceiros, o retorno diminui. Essa tendência sinaliza que a empresa mais alavancada tem maior lucratividade e maior retorno;

d) o uso escalonado das séries, com deslocamento dinâmico, com intervalo de oito anos, permite observar, como na Tabela 4, o menor uso do capital de terceiros pelas empresas com controle privado nos períodos de 2003 a $2010(0,0371)$ e 2004 a 2011 (0,0709), bem como o menor uso de capital próprio no período de 2002 a 2009 (0,1921). Uma das ocorrências relevantes no ano de 2002 foi o término do governo do partido neoliberal no Brasil (PSDB); em 2003 e 2004 foram os dois primeiros anos do governo do partido conservador (PT). A relevância dessa ocorrência está na visão oposta sobre privatização e desestatização das duas formas de governar;

Como possíveis limitações da pesquisa estão a representatividade de amostra, $47,76 \%$ do total de firmas do negócio de energia elétrica no Brasil (67,74\% com controle privado e 32,67\% com controle governamental); a interferência governamental não permitindo a liberdade de preços; e os diferentes modelos de gestão das firmas com controle privado e governamental que podem interferir nas restrições ou preferências pelas formas de financiamento.

Os resultados trazem significativas contribuições para análise das formas de financiamento das empresas do negócio de energia elétrica no Brasil. Entre essas contribuições destaca-se a inovação dos indicadores UPC e RPC na dinâmica do uso do capital próprio e de terceiros. Esses dois indicadores se relacionam de forma inversa, ou seja, quando UPC cresce, RPC diminui e vice-versa, mostrando que um é sensível ao comportamento do outro, como mostra a Tabela 4.

Finalmente, sugere-se que futuras pesquisas possam investigar a razão dessa forma de financiamento, obtendo maior poder explicativo para preferência por capital próprio ou limitação ao maior uso do capital de terceiros, e ainda se o baixo retorno do investimento combinado com o custo do capital de terceiros poderia ser uma das causas para as interrupções do fornecimento de energia elétrica que tem ocorrido com frequência.

\section{REFERÊNCIAS}

AHN, S., DENIS, D. J., DENIS, D. K. Leverage and investment in diversified firms. Journal of financial Economics, 79(2), 317-337, 2006.

ALBUQUERQUE, A. A. de. Alavancagem financeira e investimento: um estudo nas empresas brasileiras não financeiras de capital aberto. Tese (Doutorado em Administração de Organizações), Faculdade de Economia, Administração e Contabilidade de Ribeirão Preto, Universidade de São Paulo, Ribeirão Preto. Disponível em: <http://www.teses.usp.br/teses/disponiveis/96/96132/tde-28032013-100346/>. Acesso em: 2014-08-04, 2013.

ARAÚJO, J. L. de. A questão do investimento no setor elétrico brasileiro: reforma e crise. Nova economia, 11(1), 2001.

BARROS, Lucas Ayres Barreira de Campos. Decisões de financiamento e de investimento das empresas sob a ótica de gestores otimistas e excessivamente confiantes. 2005. Tese (Doutorado em Administração) - Faculdade de Economia, Administração e Contabilidade, University of São Paulo, São Paulo, 2005. Disponível em: $<\underline{\text { http:// }}$ www.teses.usp.br/teses/disponiveis/12/12139/tde-07082007-224658/>. Acesso em: 2016-08-05.

BASTOS, D. D., NAKAMURA, W. T., BASSO, L. F. C. Determinants of capital structure of publicly-traded companies in latinamerica: an empirical study considering macroeconomic and institutional factors. Revista 
de Administração Mackenzie, São Paulo, 10(6), 47-77, 2009.

BM\&F BOVESPA . Informe Técnico - MAIO/2014 - Ações mais Lucrativas - No Mês. Bolsa de Mercadorias e Futuros Bolsa de Valores de São Paulo, São Paulo. Disponível em: <http://www.bmfbovespa.com.br/ciaslistadas/empresas-listadas/BuscaEmpresaListada.aspx?idioma=pt-br>Acesso em: 2 junho 2014.

.Empresas Listada - Setor de Atuação. Bolsa de Mercadorias e Futuros Bolsa de Valores de São Paulo, São Paulo. Disponível em: <http://www.bmfbovespa.com.br/shared/IframeHotSiteBarraCanal. aspx?altura=900\&idioma=pt-br\&url=www.bmfbovespa.com.br/informe/default.asp $>$ Acesso em: 26 de maio 2014.

BRASIL. ANEEL. Resolução Normativa n 592. Custos do capital próprio e de terceiros e critérios para aferição da estrutura de capital na definição da receita teto das licitações, 2013.

Nota Técnica no 472-SRE/ANEEL. Critérios e procedimentos para cálculo do custo de capital na definição da receita teto das licitações, 2013.

BRITO, G. A. S.; CORRAR, L. J.; BATISTELLA, F. D. Fatores determinantes da estrutura de capital das maiores empresas que atuam no Brasil. Revista Contabilidade e Finanças, São Paulo, 43, 9-19, 2007.

BROOKS, C. Introductory Econometrics for Finance. 2. ed. Cambridge: Cambridge University Press, 2008.

CANZIAN, F. Nos EUA, blecaute em 2003 durou mais de 90 horas. Folha de São Paulo, São Paulo, nov, $13,2009$. Disponível em: http:/www1.folha.uol.com.br/fsp/cotidian/ff1311200923.htm. Acesso em: 21 nov 2014.

CORREA, C. A.; BASSO, L. F. C.; NAKAMURA, W. T. The capital structure of largest Brazilian firms: an empirical analysis of the Pecking Order and trade-off theories, using panel data. Revista de Administração Mackenzie, 14(4), 106-133, 2013.

DURAND, D. Costs of debt and equity funds for business: Trends and problems of measurement. In: Conference on Research in Business Finance, NBER, 215-262,1952.

FAMA, E. F., FRENCH, Kenneth R. Testing trade-off and pecking order predictions about dividends and debt. Review of financial studies, 15(1), 1-33, 2002.

FAMÁ, R., BARROS, L., SILVEIRA, A. A Estrutura de Capital é Relevante? Novas Evidências a partir de dados norte-americanos e latino-americanos. Caderno de Pesquisas em Administração, São Paulo, 8(2), 71-84, 2001.

FERREIRA, M. A., VILELA, A. S. Why do firmshold cash? Evidence from EMU countries. European Financial Management, 10(2), 295-319, 2004.

FIGUEIREDO, G. de. Determinantes da composição do endividamento de longo prazo das empresas brasileiras listadas na Bolsa de Valores de São Paulo: uma abordagem empírica. 2007. Dissertação (Mestrado em Administração) - Curso de Pós-Graduação em Administração, Faculdade de Economia, Administração e Contabilidade da Universidade de São Paulo, São Paulo, 2007.

HIROTA, H. H. O mercado de concessão de transmissão de energia elétrica no Brasil. 2006. Dissertação (Mestrado em Economia Aplicada) - Curso de Pós-Graduação em Economia, Faculdade de Economia, Administração e Contabilidade de Ribeirão Preto, Universidade de São Paulo, Ribeirão Preto, 2006. Disponível em: <http://www.teses.usp.br/teses/disponiveis/96/96131/tde-26042007-114337/>. Acesso em: 24 jun 2014.

HOVAKIMIAN, A., OPLER, T., TITMAN, S. The debt-equity choice. Journalof Financial and Quantitative analysis, 36(1), 1-24, 2001.

IARA, R. N. Análise da estrutura de capital em empresas brasileiras com diferentes níveis de endividamento: um estudo comparativo entre as teorias pecking order e trade off. 2013. Dissertação (Mestrado em Controladoria e Contabilidade) - Curso de Pós-Graduação em Controladoria e Contabilidade, Faculdade de Economia, Administração e Contabilidade de Ribeirão Preto, Universidade de São Paulo, Ribeirão Preto, 2013. Disponível em: <http://www.teses.usp.br/teses/disponiveis/96/96133/tde-23012014-105642/>. Acesso em: 22 jun. 2014.

IBGE. Indicadores IBGE Contas Nacionais Trimestrais. Instituto Brasileiro de Geografia e Estatística. Disponível em: <ftp://ftp.ibge.gov.br/Contas_Nacionais/Contas_Nacionais_Trimestrais/Fasciculo_Indicadores_IBGE/ pib-vol-val_201402caderno.pdf $>$ Acesso em: 5 ago. 2014. 
IQUIAPAZA, R. A., AMARAL, H. F., ARAUJO, M. da S. B. de. Testando as previsões da Pecking Order Theory no financiamento das empresas brasileiras: uma nova metodologia. RAM, Rev. Adm. Mackenzie, São Paulo , 9(3), 2008.

JOSKOW, P. L. Electricity sector restructuring and competition: lessons learned. Cuadernos de Economia, 40(121), 2003.

MEDEIROS, O. R., DAHER, C. E. Testando teorias alternativas sobre a estrutura de capital nas empresas brasileiras. RAC-Revista de Administração Contemporânea, 12(1), 2008.

MODIGLIANI, F., MiLLER, M. H. The cost of capital, corporation finance, and the theory of investment. American Economic Review, 48(3), 1958.

MYERS, S. C. Capital structure. The Journal of Economic Perspectives, Nashville, 15(2), 81-102, 2001.

MYERS, S. C. The capital structure puzzle. The journal of finance, 39(3), 574-592, 1984.

PEROBELLI, F. F. C., FAMÁ, R. Determinantes da estrutura de capital: aplicação a empresas de capital aberto brasileiras. Revista de Administração, 37(3), 2002.

RAJAN, R. G., ZINGALES, L. What Do We Know about Capital Structure? Some Evidence from International Data. National bureau of economic research, 50(5), 1421-1460, 1995.

SILVA, Bruno Gonçalves da. Evolução do setor elétrico brasileiro no contexto econômico nacional: uma análise histórica e econométrica de longo prazo. 2011. Dissertação (Mestrado em Energia) - Curso de PósGraduação em Energia, Universidade de São Paulo, São Paulo, 2011. Disponível em: <http://www.teses. usp.br/teses/disponiveis/86/86131/tde-12032012-091848/>. Acesso em: 10 de jul.de 2015.

SILVESTRE, Bruno dos Santos et al. Privatização: Bom ou Ruim? Lições do Setor de Distribuição de Energia Elétrica do Nordeste Brasileiro. Revista de Administração de Empresas, v. 50, n. 1, p. 94, 2010. 